\title{
Contributions of business process management promotion techniques to knowledge management: empirical evidence
}

\author{
Ana Augusta Almeida de Souza dos Santos ${ }^{1}$, Silvia Inês Dallavalle de Pádua , \\ Ronaldo Bernardo Junior², Emerson Lima Aredes ${ }^{3}$ \\ ${ }^{1}$ School of Economics, Administration and Accounting, University of São Paulo, Ribeirão Preto, Brazil. \\ ${ }^{2}$ Federal Center for Technological Education of Rio de Janeiro (CEFET-RJ). \\ ${ }^{3}$ School of Economics, Administration and Accounting, University of São Paulo, Ribeirão Preto, Brazil.
}

How to cite: Santos, A.A.A.S., Pádua, S.I.D., Bernardo Junior, R. et al. (2020), “Contributions of business process management promotion techniques to knowledge management: empirical evidence", Brazilian Journal of Operations \& Production Management, Vol. 17, No. 03, e2020987. https://doi.org/10.14488/BJOPM.2020.034

\begin{abstract}
Goal: Knowledge Management (KM) has been increasingly used by organizations to help innovation and gain competitive advantage; however, the implementation of KM may turn in bad results, because of functional isolation. In contrast, Business Process Management (BPM) is an approach that removes functional isolation, establishing end-to-end processes perspective through cycle promotion and usage of management techniques. Therefore, the aim is to understand how the techniques used to promote BPM contribute to KM.
\end{abstract}

Design/ Methodology/ Approach: In step 1, a systematic review of the literature was carried out on the scientific bases, trying to understand how the literature dealt with the relationship between BPM and $\mathrm{KM}$ techniques in the last 10 years. In step 2, there was a project to promote BPM in a public hospital. Stage 3 sought to understand the leaders' perceptions about the possible contributions of BPM techniques to KM.

Results: BPM acts promoting participation and sharing (social aspects); collecting information about the organization and identifies problems (cognitive aspects); allowing decision making to solve problems (strategic aspects); explaining tacit information, organizing and compiling explicit information (technological aspects) in order to enable changes in systems.

Limitations of the investigation: Single case study.

Practical implications: BPM project collaborates to expand the diversity of information sources, opens the organization to external knowledge, with external consultant's participation, also it provides communication expanding between areas, thus, improving customer service.

Originality/ Value: This work contributes to show a valuable combination of techniques and how each one contributes to an essential resource as knowledge.

Keywords: Knowledge Management; Business Process Management; Techniques.

\section{INTRODUCTION}

Business environments are becoming more dynamic (Fiorentino, 2016; Bernardo et al., 2017), and organizations need to adopt improved management practices (Barney, 1991; Dutta, 2015). Knowledge management (KM), which consists of a set of organizational practices that promote learning and organizational knowledge (Ferguson et al., 2010) favoring innovation and the achievement of sustained competitive advantages (Sadeghi et al., 2013). However, evidence has drawn attention to the possibilities of perfecting KM.

Financial support: Fundação de Amparo à Pesquisa do Estado de São Paulo (FAPESP) - Project number: 2018-1539-4

Conflict of interest: The authors have no conflict of interest to declare.

Corresponding author: anaaugusta.souza1@gmail.com

Received: 31 May 2020

Accepted: 26 July 2020

Guest Editors: Fernando Oliveira de Araujo and Chrystyane Abreu 
Up to $84 \%$ of the initiatives of KM implementation do not present relevant results (Lucier and Torsilieri, 1997, Ambrósio, 2000), and one of the main reasons is functional isolation. In this aspect, business process management (BPM) can contribute because it removes functional isolation by approaching organizational processes in an end-to-end perspective (Maddern et al., 2014). BPM represents an organizational effort "to analyze and continually improve fundamental activities such as manufacturing, marketing, communications and other major elements of company's operations" (Trkman, 2010, p. 125).

BPM has been receiving more and more attention from managers and researchers (McCormack et al., 2009; Lehnert et al., 2014) by improving processes and allowing the organization to understand them within the strategy (Silva et al., 2012; Rosemann and Vom Brocke, 2015), adopting the outside-in view (Islam and Ahmed, 2012), eliminating information flow problems (Massingham and Al Holaibi, 2017), and explaining systemic information of the organization (Segatto et al., 2013).

Only through a holistic view can we understand the interaction between tacit knowledge (individual experience) and explicit knowledge, expressed in documents, rules, and standards (Nonaka, 1994; Nonaka and Toyama, 2003). In this regard, BPM represents a key initiative for the development of KM (Kalpič and Bernus, 2006) because it organizes the flow of organizational activities-both those based on explicit knowledge and those based on tacit knowledge (Chilton and Bloodgood, 2008).

It should be noted that the promotion of BPM has a cycle composed of six stages: planning, analysis, design, implementation, control, and refinement (Morais et al., 2014). Different techniques assist in the execution of each of these six stages of the BPM cycle (Bernardo et al., 2017).

From the above, a question emerges: How do the techniques used to promote BPM contribute to $\mathrm{KM}$ ? In order to shed light on this issue, the aim of the present study is to describe empirical evidence as to how the techniques used to promote BPM contribute to KM.

For the present research, the case of the promotion of BPM in a Brazilian public hospital was studied between the years of 2016 and 2017. The Brazilian health sector operates in increasingly dynamic environments, so institutions need to properly read the environment and prepare their structure to deal with increasing complexity.

\section{BUSINESS PROCESS MANAGEMENT PROMOTION}

BPM is a management approach capable of bringing external insight into organizations (Islam and Ahmed, 2012), also, it makes possible to prevent the occurrence of errors in information quality, to create metrics, to interrelate processes, and to clarify where and what the deficiencies of the processes are (Gogan et al., 2013).

The success of the BPM project depends on many factors, and one of them is the organizational context, because different business contexts will require different actions by the project team, as the environment, organization, objectives, and processes can be different (Vom Brocke et al., 2016). Another critical success factor is the active participation of organizational members during BPM projects (Silva et al., 2012).

BPM is promoted in organizations through a cycle (Bernardo et al., 2017). The description of the stages of the BPM cycle is presented in Table 1, and the techniques used at each stage are described below. 
Table 1. Stages of the BPM life cycle.

\begin{tabular}{|c|c|}
\hline Stage & Description \\
\hline Planning and strategy & $\begin{array}{l}\text { Establish a strategy oriented toward business processes and develop a } \\
\text { plan to direct BPM actions. }\end{array}$ \\
\hline $\begin{array}{l}\text { Analysis of business } \\
\text { processes }\end{array}$ & $\begin{array}{l}\text { Use different methodologies to understand the current alignment of } \\
\text { organizational processes with the stipulated objectives and goals. }\end{array}$ \\
\hline Design & $\begin{array}{l}\text { Design the new process and its specifications; strive to adjust the } \\
\text { specifications within a model that best contributes to the objectives } \\
\text { established in the plan based on the current status. }\end{array}$ \\
\hline $\begin{array}{l}\text { Process } \\
\text { implementation }\end{array}$ & $\begin{array}{l}\text { Implement the adjusted model. This stage includes the challenges of } \\
\text { change management and process optimization. }\end{array}$ \\
\hline $\begin{array}{l}\text { Control and } \\
\text { monitoring }\end{array}$ & $\begin{array}{l}\text { Contrast the achieved results with the planned goals and offer suggestions } \\
\text { for decision-making by managers and continuous improvement. }\end{array}$ \\
\hline Refining & $\begin{array}{l}\text { Make adjustments and improvements to contribute more effectively to } \\
\text { cycle feedback. }\end{array}$ \\
\hline
\end{tabular}

Source: Adapted from Association of Business Process Management Professionals (2013).

Planning a BPM project is based on the organization's understanding of stakeholder identification, strategy (e.g., objectives, vision, mission), how processes are distributed, and which processes are prioritized for analysis and modification (Morais et al., 2014). A technique for understanding the organization's modus operandi is the business model canvas (BMC), which is used for rapid and interactive development/knowledge about the logic of how the organization creates, delivers, and captures value (Osterwalder and Pigneur, 2010; O'Neill, 2015). Process architecture (PA) is another technique for visualizing organizational processes that shows the components of processes, identifies patterns and relationship association (Barros and Julio, 2011), ensures the alignment of strategies, and processes and supports resources contributing to the success of BPM (Aredes and Pádua, 2014).

Subsequently, with the identification of the internal and external environment in which the organization operates, there is also analysis of the necessary modifications through the techniques of problem diagnosis (Grant, 2016). The value stream mapping (VSM) technique is responsible for identifying unnecessary activities in the organization's flow of value and the time required to carry out the activities (Hines and Rich, 1997). Another diagnostic technique is the current reality tree (CRT) responsible for representing a cause-and-effect logic (Silva and Sellitto, 2010), identifying the micro and macro problems of a process, and making it possible to identify root causes (Pádua et al., 2014). The techniques have different objectives, then they can visualize different dimensions such as processes, technology, people, communication, and structure (Grant, 2016). Process modeling (PM) is a technique that allows the organization to document and visually divide processes (Flowers and Edeki, 2013) and that therefore helps in promoting isolated improvements at certain points of inefficiency (Pádua et al., 2014) in understanding and communicating the organization (Indulska et al., 2009); the PM is used in the as-is approach to process analysis and in the to-be approach to process design.

Pain/gain matrix (PGM) allows the identification of the most critical processes for the fulfillment of the strategic objectives and the generation of value, as well as the painful processes that are part of the performance but are far from the ideal (Burlton, 2010). The importance-performance matrix (IPM) is important to confront the performance of an organization's services/products against the competition with the importance that the consumer market attaches to each element (Prajogo and McDermott, 2011) in order to highlight the challenges involved in the strategic choice (Prajogo and McDermott, 2011).

The process implementation stage may or may not occur because it depends on positive factors to impose it. There are four important cultural aspects for the improvements that should be implemented by the organization: customer orientation, excellence, responsibility, and teamwork (Schmiedel et al., 2013). Customer orientation shows that the organization considers the external environment; teamwork is related to the internal focus of collaboration; 
excellence defines continuous orientation for improvement and innovation, emphasizing the constant flexibility to promote changes that increase performance; and responsibility refers to the commitment of organizational members (Schmiedel et al., 2013). Excessive bureaucracy, lack of leadership involvement, and lack of involvement of other organizational members are examples of organizational factors that can disrupt the implementation of BPM (Sentanin et al, 2008; Syed et al., 2017).

The control and monitoring stage identifies the differences between what was planned and the results obtained. In general, BPM is promoted from the perspective of projects (Hernaus et al., 2016) so that at this stage there is the widespread use of Spreadsheet (SS), which through graphics enables the visualization of the status reached by the team. From the differences between what was planned and what was achieved, the organization performs a refinement in the results to respond to the planning so as to be more assertive in the continuity of the cycle. A widely used technique for refinement is the action plan (AP), applied for the purpose of forwarding future improvements. One of the most used models of AP comes from the area of quality, known as $5 \mathrm{~W} 2 \mathrm{H}$, which helps to describe the following: What will be done, as well as When, Who, Where, Why, How, and How much (Boer and Blaga, 2012). After the refinement stage, the cycle is restarted (Morais et al., 2014).

\section{KNOWLEDGE PROCESS MANAGEMENT}

The goal of KM is to make explicit knowledge accessible through systems or databases, as well as to ensure an organizational culture that facilitates the sharing of tacit knowledge (Bollinger and Smith, 2001). The viability of KM depends on a holistic approach that must contemplate four environmental conditions: social condition, strategic condition, cognitive condition, and information systems (Choo and Alvarenga Neto, 2010).

Social conditions is related to build a trust and a tolerant mistakes environment to improve social relationship (Choo and Alvarenga Neto, 2010), as the interpersonal relations contribute to the creation and transfer of the knowledge between the organizational members (O'Brien, 2015). Making tacit knowledge accessible requires the use of individual-oriented strategies such as encouraging collaboration, building trust, and exchanging knowledge among people (Lee and Choi, 2003; Tsoukas and Vladimirou, 2001). Some strategies used to stimulate interpersonal relationships include communities of practice (Bollinger and Smith, 2001), workshops (Manfreda et al., 2015), and brainstorming sessions (Pathirage et al., 2006). Encouraging socialization means facilitating the acquisition of tacit knowledge through sharing in informal and formal meetings (Nonaka et al., 2000).

Strategic conditions allows organizational members to think about the activities that will provide support for KM, such as stimulating teamwork, creating meeting spaces (Choo and Alvarenga Neto, 2010), elaborating on the projects and tasks that depend on the intense exchange of knowledge (to break the barriers that prevent sharing) (Michailova and Husted, 2001), and modifying internal structures through the adoption of systems that share simultaneous information (Kim et al., 2014). All these actions are strategic for knowledge and aim to improve the efficiency of work processes and to reduce the time time it takes to access knowledge to develop work activities (Massingham and Al Holaibi, 2017).

Cognitive conditions are formed by the diversity of sources of information, diversity of perspectives, and level of openness of the organization (Choo and Alvarenga Neto, 2010). Organizations have cognitive assets that are raw materials for future processing and transformation into capabilities that ensure greater organizational performance (Wu and Chen, 2014), such as the example of industries in the high technology sector that prioritize structures facilitating the internalization of external knowledge (Liao et al., 2017). Internalization is the process that converts explicit knowledge into tacit knowledge so that the individual can make that knowledge ready in new knowledge (Nonaka et al., 2000). Outsourcing, on the other hand, is the process of making tacit knowledge explicit knowledge for the creation of new products, for example (Nonaka et al., 2000). 
Information systems are important because explicit knowledge can be easily transferred through them (Maruta, 2014), as it refers to information known as, for example, operating results, processes, and routines (Gaspar et al., 2009). Another way of characterizing explicit knowledge is by recognizing its formalization capacity, which means the possibility of dividing or decomposing it into structured processes (Kalpič and Bernus, 2006). This process of explicit knowledge decomposition is called a combination and can result in a handbook or turn a concept into a practice (Nonaka et al., 2000). Information systems generalize and standardize existing knowledge and can enable the elimination of redundancies through the simultaneous sharing of information (Kim et al., 2014).

KM has a positive impact on process innovation (Al'sadi et al., 2017), so it is important for the maintenance of organizational competitiveness (Teece, 2007). The valuation of BPM depends on the understanding and perception that it is a management approach capable of sustaining competitive advantages (Lacerda et al., 2016). The BPM promotion project itself is conducted in a cycle that begins with the organization's knowledge (Morais et al., 2014). Thus, it is understood that BPM and KM contribute to one another; thus, they become able to respond and create a virtuous cycle for the organization.

\section{METHOD}

The objective of the present study is to describe empirical evidence about how the techniques used to promote BPM contribute to KM, specifically to the four environmental conditions of KM (social condition, strategic condition, cognitive condition, and information systems), (Choo and Alvarenga Neto, 2010). For that, the social, strategic, cognitive, and information systems conditions of KM were analyzed through the information collected by BPM promotion techniques, in the case of a Brazilian public hospital. The case study protocol is presented in Table 2 .

Table 2. Study case protocol.

\begin{tabular}{|c|c|}
\hline Element & Description \\
\hline Research question & How do the techniques used to promote BPM contribute to KM? \\
\hline Unity of analysis & Empirical evidence on the contributions of a project to promote BPM to KM. \\
\hline Time period & Years of 2016 and 2017. \\
\hline Site & Public Brazilian Hospital. \\
\hline Validation & Contrast between theory and practice. \\
\hline Internal validation & Use of multiple sources of evidence. \\
\hline Method & Document analysis, semi-structured interviews and observation. \\
\hline Proposition & $\begin{array}{l}\text { The techniques used to promote BPM create social, strategic, cognitive and } \\
\text { information systems that collaborate for KM. }\end{array}$ \\
\hline Secondary questions & $\begin{array}{l}\text { (i) What are the contributions of BPM promotion techniques to the social } \\
\text { conditions of KM? } \\
\text { (ii) What are the contributions of BPM promotion techniques to the strategic } \\
\text { conditions of KM? } \\
\text { (iii) What are the contributions of BPM promotion techniques to the } \\
\text { cognitive conditions of KM? } \\
\text { (iv) What are the contributions of BPM promotion techniques to KM's } \\
\text { information system conditions? }\end{array}$ \\
\hline
\end{tabular}

Source: Authors, 2019.

The elaboration of this study took place in three stages. In stage 1, the objective was to understand how literature has addressed the relationship between BPM techniques and KM. For this purpose, a systematic review of the literature (Jones, 2004) in the Science Direct and Scopus databases was carried out in peer-reviewed journals published in English in the last 10 years, searching the topics (Science Direct) and keywords (Scopus): << Business Process 
Management $>>$, OR $<<$ BPM $>>$; AND $<<$ Knowledge Management $>>$. Two filters were applied, $\mathrm{F} 1$ being the reading of the title, abstract, and keywords and F2 being the reading of the entire text, and redundancies were excluded. Of all the 2,367 initial occurrences in Science Direct, as well as the 3,837 early occurrences in Scopus, no publication linking BPM techniques to KM was identified.

In stage 2, the research was performed. For the case study, a BPM promotion project was implemented in a Brazilian public hospital, as it was a quality organization that has undergone major transformations in recent years. The project took place during the years 2016 and 2017; data collection took place through eight meetings with an average duration of 60 minutes each and included direct observation and analysis of documents. The meetings were always attended by two leaders at the board level, specifically the medical director and the director of nursing. In addition to these professionals, the neonatology supervisor, the hospitalization supervisor, and the hospital's hospitality director participated in the study.

In stage 3, the study consisted to searching how the leaders understood the possible contributions of BPM techniques to the management of organizational knowledge. For this, the data were collected through a structured interview script.

\section{RESULTS}

The results are described in two subsections called "planning and strategy," and "analysis of business process." These subsections represent an initial phase of the BPM promotion cycle that due to the organization's limitations was not made in its entirety. The subsection "planning and strategy" describes the application of two techniques: BMC and PA. "Analysis of business process" aims to demonstrate the techniques used to discover organizational problems such as CRT, PM, and VSM, and prioritize improving the problems found through two matrices: PGM and IPM.

\section{Planning and strategy}

This phase had four meetings for its execution. The first two meetings were devoted to discuss strategic knowledge of the hospital. At the first meeting, the director of nursing and the physician were present and showed full understanding about the hospital, answering without difficulty the questions to realize the business model canvas (BMC).

The BMC was seen as a democratic technique that enables the participation, discussion, and organization of ideas. "Canvas is an exercise in organization and discussion, and notepad blocks allow discussion with the team, so that they know what each one thinks. Canvas is a tool in which everyone can participate from strategic to operational" (the medical leader).

Two other meetings were needed to develop the PA. Central processes have a standardization, so they were easily described by leaders. The difficulty lies in describing the life cycle of two essential support processes for the central processes, namely the laundry processes and the nutrition/feeding processes. Two people responsible for these processes have been called upon to assist in describing the life cycle of these processes.

PA had a unanimous perception, as both the medical leader and the nursing leader understand that the figure of architecture has the function of representing reality in a didactic way for the other organizational members: "Architecture is the one that adds more value by the visual enabling membership to see the organization" (the medical leader).

\section{Analysis of business processes}

The objective of this stage of the study was to detail the causes that may be affecting the strategic area of the clinic. The modeling technique that used the BPMN notation identified two problems in the operation of the outpatient clinic, namely the lack of monitoring by indicators on the time patients spend inside the hospital until they are released and the patients' long waiting period to be attended. The modeling has points of disagreement among the leaders. For the medical leader, BPMN process modeling is just a flow documentation, 
whereas for the nursing leader, modeling is able to "organize information in a didactic way and cause reflection on the process."

The VSM technique identified points of wasted time related to the outpatient clinic. One problem is the generation of overtime by the employees involved in the outpatient process due to the lack of attention and control of the scales. Another problem is related to the need for a large movement of papers with patient care records. This problem will be constant until everything is properly digitized in a system, as the digitization process of the medical records began in 2014 and all the history before that date is not up to date. The third problem that appeared in this technique is equal to the second problem of the BPMN technique, which is the long waiting time for the patient to perform the medical consultation. The VSM is a technique that allows the patient "to make a reflection on each point of the process" according to the medical leader.

The CRT technique identified the most problems in the ambulatory area, which totaled twenty-five, but that can be summarized in three root causes: absence of a unified program of communication, absence of end-to-end process management, and difficulty managing human, financial, and material resources. The problem of communication lies in the insufficient number of plaques and other signs that help in the transit of the patients and in the absence of a system that educates the doctors and the patients on the cancellation of consultations done by one or the other.

The CRT, on the other hand, is not seen as an adequate tool to present to the team; according to the nursing leader, CRT has difficult visual interpretation: "[CRT] is a tool that puts everything in a tangle and has no idea why or where to start solving. It is less effective in the exchange of knowledge, and it is more difficult to present." Table 3 summarizes the problems found in the ambulatory area.

Table 3. Problems identified by techniques.

\begin{tabular}{|c|c|c|c|}
\hline \multirow{2}{*}{ Problems } & \multicolumn{3}{|c|}{ Techniques } \\
\hline & VSM & PM & CRT \\
\hline Long waiting period for patients until medical attention. & $x$ & $\mathrm{X}$ & $\mathrm{x}$ \\
\hline Generation of overtime employees involved in the service process. & $x$ & & $\mathrm{X}$ \\
\hline Non-systematic evaluation of medical records. & $x$ & & $x$ \\
\hline $\begin{array}{l}\text { Difficulty in the management of human, financial and material } \\
\text { resources. }\end{array}$ & & & $x$ \\
\hline Absence of unified communication program. & & & $x$ \\
\hline Lack of end-to-end process management. & & & $x$ \\
\hline
\end{tabular}

Source: Research data (2017).

PGM has engaged other people as well, and direct processors have been called in to give the notes and thereby achieve a realistic perception of the pain and gain of the processes. The result of strategic alignment has been the identification of essential parts of the life cycle of the core processes that must be observed in order for the strategic objectives linked to them to be realized. Regarding PGM, the nursing leader stressed the need for the participation of people from the areas of process interface, and the medical leader supplemented that the values of PGM are based on experience.

Also important was the application of IPM, due to the lack of knowledge about this technique, an explanation was given to the three leaders present. After leadership finished the evaluation process, each member provided an exposition of the notes for the items. This exposure led to a debate about the reasons for large differences in certain items, and the debate helped to bridge the gap between the bills.

According to leadership, BPM techniques have helped manage and promote knowledge about the hospital. The medical and nursing directors had the unanimous perception of the 
need to carry out a self-assessment, as well as the need to reflect and bring personal experience to the foreground when assigning a grade in IPM.

\title{
DISCUSSION
}

The case study demonstrated that the context influences the performance of the project team. This corroborates with Vom Brocke et al. (2016), given that, despite the literature showing the cycle to be followed, time constraints, coupled with low management autonomy and human and financial resource constraints, make it impossible in this specific case to implement changes in processes in the short term.

The BPM promotion project in the context of "Brazilian public hospital," in the short term, collaborated toward triggering socialization processes (Nonaka et al., 2000). The project also collaborated in order for leadership to think of ways to expand communication (Choo and Alvarenga Neto, 2010) between areas that need to share information and thus improve customer service. Another collaboration observed in this case was to break down barriers that impeded the sharing of information (Michailova and Husted, 2001).

IPM contributed to promoting reflection and brought personal experience to the surface at the time of assigning a grade to the performance of organizational areas. The array IPM combined with the array PGM had great importance for socializing, as well as to break the barrier of the lack of time for information sharing that existed between those responsible for different assignments. Another contribution of both techniques was the promotion of knowledge externalization, thus making tacit knowledge explicit knowledge (Nonaka et al., 2000).

BPM helped the organization to act strategically in reducing the access time to knowledge (Massingham and Al Holaibi, 2017). Through CRT and VSM, technical problems were identified with the records, which influenced the leadership to generate a solution, as exemplified by the speech of the medical leader: "[VSM] allows you to perform a reflection on every point." The BPM promotion project has shown that the information won through meetings and interviews helped to expand the diversity of information sources and opened the organization to share and exchange knowledge with external consultants, thus contributing to KM (Choo and Alvarenga Neto, 2010). End-to-end process management is still under construction, as the workload makes it unfeasible to dedicate the team to the BPM project. The nursing leader's speech emphasizes this point:

\begin{abstract}
"The health area lacks a professionalization of management, and systems are still geared towards an end attention. The tools help you identify the process node. It is not so simple to apply these tools for the amount of exceptions that can arise in the processes due to the personalized attention to the patient. Assertive decisions considering process modeling have already been taken, bringing positive results, significantly reducing discharge time, and organizing processes [in other known hospitals]. However, the frequency with which it needs to hold meetings to elaborate the information of the tool prevents the deepening of the result". (Nursing leader's speech)
\end{abstract}

The study showed that the identification of processes critical to organizational performance requires the participation of people from different areas of the organization because there is a need for tacit knowledge to measure gains. The application of the study was especially important in a hospital, which is an environment that includes professionals with the most varied formations and specialties allocated at several hierarchical levels, in order to form a very complex organizational environment.

The problem of overtime generation of employees involved in the service process was solved, mainly by the pressure exerted by the human resources area. Scale monitoring is done daily and informally. Meetings have been one method used to improve communication between receptionists, care staff, and patients, with conversation being the main means of passing work routines to receptionists. The patients' long waiting period was mitigated by the 
monitoring of the scales and by the abstraction of non-systematized cases to reduce the need for transferring large quantities of documents.

However, the lack of real-time indicator systems of patients entering and leaving the system is still a problem that can continue to generate waiting on the part of patients. The permanence in the difficulty of managing human, financial, and material resources is another point that also affects the quality of the service, as, being a public organization, the hiring of new employees awaits legal permission, thus making the hiring process slow. Also, the purchase of materials depends of government spending that is often insufficient.

The information gained through the stages of the BPM project collaborated to expand the diversity of information sources and opened the organization to external management knowledge, with the participation and exchange of knowledge by external consultants, contributing to knowledge management (Choo and Alvarenga Neto, 2010). They also collaborated so that the leadership could think of ways to expand communication (Choo and Alvarenga Neto, 2010) between areas that need to share information and, thus, improve customer service. Another collaboration was in the sense of breaking down barriers that prevented the sharing of information (Michailova and Husted, 2001). In this way, the BPM project enabled the organization to compile the information of the stages to reach social, strategic, cognitive and systems conditions for the development of KM and modify the organizational processes based on the knowledge improving (table 4).

Table 4. Summary of the results.

\begin{tabular}{|c|c|c|c|c|c|}
\hline \multicolumn{2}{|c|}{ Business Process Management } & \multicolumn{4}{|c|}{ Knowledge Management } \\
\hline Stage & Technique & Social & Strategy & Cognitive & Systems \\
\hline \multirow{2}{*}{ Planning and strategy } & - B.M. Canvas & - & $\square$ & $\square$ & $\square$ \\
\hline & - P.A. & - & $\square$ & $\square$ & $\square$ \\
\hline \multirow{5}{*}{$\begin{array}{c}\text { Analysis of business } \\
\text { processes }\end{array}$} & - VSM & $\square$ & - & • & $\cdot$ \\
\hline & - CRT & $\square$ & - & • & - \\
\hline & - Modelling As Is & $\square$ & • & • & $\cdot$ \\
\hline & - Pain and Gain & - & $\square$ & • & $\square$ \\
\hline & - IPM & - & $\square$ & - & $\square$ \\
\hline
\end{tabular}

Subtitle: • Excellent contribution; - Good contribution; ○ Low contribution; $\square$ Without contribution.

Source: Research data (2017).

\section{CONCLUSION}

The results present empirical evidence of the contributions of the BPM techniques to the environmental conditions of KM. The BPM promotion project made it possible to create social, strategic, cognitive, and technological conditions for KM. This is because BPM acts in the promotion of participation and sharing (social aspect), mainly in the planning and strategy and design stages. The BPM promotion project also increases access to information about the organization by identifying problems, allowing the participation of organizational members in different hierarchical levels and functional departments, and increasing the sources of knowledge from the organization (cognitive aspect). The BPM promotion project also allows external knowledge adsorption, as the consultants spread knowledge about how to use and when to use management techniques (cognitive aspect). It was possible to realize the cognitive aspect in the three initial stages, which are planning and strategy, analysis of business processes, and design.

The refining stage showed to be an important phase to promote the strategy and system aspects of KM. This stage allowed hospital leaders to make decisions to solve problems, and informal and formal meetings were one way to deal with a lack of knowledge, so the BPM promotion project made it possible for the KM strategic decision. The refining stage also made the need to systematize information evident so as to accurately coordinate patient waiting 
times, which is a problem still present due to a lack of financial resources, but it is also an example of how BPM helps to develop aspects of systems in the organization and collaborates with KM development in all aspects.

In the context studied, the applied techniques demonstrated an important function in creating the KM conditions triggered by the BPM promotion project and in the retention of information. The great amount of work, together with the lack of human, financial, and material resources, shows a context where it is necessary to consider the medium- and longterm perspectives for major changes to occur.

This study has theoretical and practical implications. The theoretical implications reside in the results, which point out that the constraints of the context must be considered when defining the scope and time to implement the modifications. The practical implications lie in the techniques used to promote BPM, which can be used for other purposes than the promotion of BPM itself. The main limitation of the present study was its application in a very specific context; thus, the application of BPM techniques must be carried out in other contexts in order to allow a comparison of the obtained results. Therefore, for future research, the application of BPM techniques in other organizations of the health sector is suggested to verify if their contributions to KM aspects are similar or different. Another suggestion is to develop more studies uniting BPM and $\mathrm{KM}$ to understand which management approach starts the development of the other. Another possible study is an empirical one that verifies KM and BPM integration during the complete BPM cycle.

\section{REFERENCES}

Al-Sa'di, A.F., Abdallah, A.B. and Dahiyat, S.E. (2017), "The mediating role of product and process innovations on the relationship between knowledge management and operational performance in manufacturing companies in Jordan", Business Process Management Journal, Vol. 23, No. 2, pp. 349-76.

Ambrosio, J. (2000), "Knowledge management mistakes", Computerworld, 3 July.

Aredes, E.L. and Pádua, S.I.D. (2014), "Process architecture as a BPM critical success factor: a bibliographic review", Business and Management Review, Vol. 4, No. 3, pp. 245-55.

Association of Business Process Management Professionals - ABPMP (2013), Guia para o Gerenciamento de Processos de Negócio Corpo Comum de Conhecimento, BPM CBOK, Brasília.

Barney, J.B. (1991), "Looking inside form competitive advantage", The Academy of Management Executive, Vol. 9, No. 4, pp. 49-61.

Barros, O. and Julio, C. (2011), "Enterprise and process architecture patterns", Business Process Management Journal, Vol. 17, No. 4, pp. 598-618.

Bernardo, R., Galina, S.V.R. and Pádua, S.I.D. (2017), "The BPM lifecycle: How to incorporate a view external to the organization through dynamic capability", Business Process Management Journal, Vol. 23, No. 1, pp. 155-75.

Boer, J. and Blaga, P. (2012), "A more efficient production using quality tools and human resources management", Procedia Economics and Finance, Vol. 3, pp. 681-9.

Bollinger, A.S. and Smith, R.D. (2001), "Managing organizational knowledge as a strategic asset", Journal of Knowledge Management, Vol. 5, No. 1, pp. 8-18.

Burlton, R. (2010), “Delivering business strategy through process management", in Vom Brocke, J. and Rosemann, M. (Ed.), Handbook on Business Process Management: Strategic Alignment, Governance, People and Culture, Springer, Berlin, pp. 5-37.

Chilton, M.A. and Bloodgood, J.M. (2008), "The dimensions of tacit \& explicit knowledge: A description and measure", International Journal of Knowledge Management, Vol. 4, No. 2, pp. 75-91.

Choo, C.W. and Alvarenga Neto, R.C.D. (2010), "Beyond the ba: managing enabling contexts in knowledge organizations", Journal of Knowledge Management, Vol. 14, No. 4, pp. 592-610.

Dutta DK. (2015), "Hypercompetitive environments, coopetition strategy, and the role of complementary assets in building competitive advantage: Insights from the resource-based view", Strategic Management Review, Vol. 9, No. 1, pp. 1-11. 
Ferguson, J., Huysman, M. and Soekijad, M. (2010), "Knowledge management in practice: pitfalls and potentials for development", World Development, Vol. 38, No. 12, pp. 1797-810.

Fiorentino, R. (2016), "Operations strategy: a firm boundary-based perspective", Business Process Management Journal, Vol. 22, No. 6, pp. 1022-43.

Flowers, R. and Edeki, C. (2013), "Business process modeling notation", International Journal of Computer Science and Mobile Computing, Vol. 2, No. 3, pp. 35-40.

Gaspar, M.A., Donaire, D., Santos, S.A.D. et al. (2009), "Um estudo dos portais corporativos como instrumento de externalização do conhecimento explícito em universidades", Revista Brasileira de Gestão de Negócios, Vol. 11, No. 31, pp. 119-33.

Gogan, J.L., Baxter, R.J., Boss, S.R. et al. (2013), "Handoff processes, information quality and patient safety", Business Process Management Journal, Vol. 19, No. 1, pp. 70-94.

Grant, D. (2016), "Business analysis techniques in business reengineering", Business Process Management Journal, Vol. 22, No. 1, pp. 75-88. http://dx.doi.org/10.1108/BPMJ-03-2015-0026.

Hernaus, T., Vuksic, V.B. and Štemberger, M.I. (2016), "How to go from strategy to results? Institutionalising BPM governance within organisations", Business Process Management Journal, Vol. 22, No. 1, pp. 173-95.

Hines, P. and Rich, N. (1997), "The seven value stream mapping tools", International Journal of Operations \& Production Management, Vol. 17, No. 1, pp. 46-64.

Indulska, M., Green, P., Recker, J. et al. (2009), "Business process modeling: Perceived benefits", in International Conference on Conceptual Modeling, Springer, Berlin, Heidelberg, pp. 458-71.

Islam, S. and Ahmed, M.D. (2012), "Business process improvement of credit card department: case study of a multinational bank", Business Process Management Journal, Vol. 18, No. 2, pp. 284-303. http://dx.doi.org/10.1108/14637151211225207.

Jones, M.L. (2004), "Aplication of systematic review methods to qualitative research: pratical issues", Journal of Advanced Nursing, Vol. 48, No. 3, pp. 271-8.

Kalpič, B. and Bernus, P. (2006), "Business process modeling through the knowledge management perspective", Journal of Knowledge Management, Vol. 10, No. 3, pp. 40-56.

Kim, T.H., Lee, J-N, Chun, J.U. et al. (2014), "Understanding the effect of knowledge management strategies on knowledge management performance: A contingency perspective", Information \& Management, Vol. 51, No. 4, pp. 398-416.

Lacerda, R.T.O., Ensslin, L., Ensslin, S.R. et al. (2016), "Research opportunities in business process management and performance measurement from a constructivist view", Knowledge and Process Management, Vol. 23, No. 1, pp. 18-30.

Lee, H. and Choi, B. (2003), "Knowledge management enablers, processes, and organizational performance: An integrative view and empirical examination", Journal of Management Information Systems, Vol. 20, No. 1, pp. 179-228.

Lehnert, M., Linhart, A. and Röglinger, M. (2014), “Chopping Down Trees vs. Sharpening the Axe Balancing the Development of BPM Capabilities with Process Improvement", in 12th International Conference, Haifa, Israel, pp. 151-67.

Liao, S.H., Chen, C.C., Hu, D.C. et al. (2017), "Developing a sustainable competitive advantage: absorptive capacity, knowledge transfer and organizational learning", The Journal of Technology Transfer, Vol. 42, No. 6, pp. 1431-50.

Lucier, C.E. and Torsilieri, J.D. (1997), "Why knowledge programs fail: A CEO's guide to managing learning", Strategy and Business, Vol. 9, No. 4, pp. 14-28.

Maddern, H., Smart, P.A., Maull, R.S. et al. (2014), "End-to-end process management: implications for theory and practice", Production Planning and Control, Vol. 25, No. 16, pp. 1303-21.

Manfreda, A., Buh, B. and Indihar Štemberger, M. (2015), "Knowledge-intensive process management: a case study from the public sector", Baltic Journal of Management, Vol. 10, No. 4, pp. 456-77. http://dx.doi.org/10.1108/BJM-10-2014-0170.

Maruta, R. (2014), "The creation and management of organizational knowledge", Knowledge-Based Systems, Vol. 67, pp. 26-34. 
Massingham, P. and Al Holaibi, M. (2017), "Embedding Knowledge Management into Business Processes", Knowledge and Process Management, Vol. 24, No. 1, pp. 53-71.

McCormack, K., Willems, J., Van Den Bergh, J. et al. (2009), "A global investigation of key turning points in business process maturity", Business Process Management Journal, Vol. 15, No. 5, pp. 792-815.

Michailova, S. and Husted, K. (2001), Dealing with Knowledge Sharing Hostility Insights from Six Case Studies, Working Paper, Copenhagen Business School, Copenhagen. pp. 1-25.

Morais, R.M., Kazan, S., Pádua, S.I.D. et al. (2014), "An analysis of BPM lifecycles: from a literature review to a framework proposal", Business Process Management Journal, Vol. 20, No. 3, pp. 412-32.

Nonaka, I. (1994), "A dynamic theory of organizational knowledge creation", Organization Science, Vol. 5, No. 1, pp. 14-37.

Nonaka, I., Toyama, R. and Konno, N. (2000), "SECl, Ba and leadership: a unified model of dynamic knowledge creation", Long Range Planning, Vol. 33, No. 1, pp. 5-34.

Nonaka, I. and Toyama, R. (2003), "The knowledge-creating theory revisited: knowledge creation as a synthesizing process", Knowledge Management Research and Practice, Vol. 1, No. 1, pp. 2-10.

O'Brien, J. (2015), "10 Practical findings from the deployment of an exploratory knowledge management framework", Vine, Vol. 45, No. 3, pp. 397-419.

O'Neill, T.W. (2015), "The business model canvas as a platform for business information literacy instruction", RSR. Reference Services Review, Vol. 43, No. 3, pp. 450-60.

Osterwalder, A. and Pigneur, Y. (2010), Business Model Generation, John Wiley and Sons, New Yersey.

Pádua, S.I.D., Costa, J.M.H., Segatto, M. et al. (2014), "BPM for change management: two process diagnosis techniques", Business Process Management Journal, Vol. 20, No. 2, pp. 247-71.

Pathirage, C., Amaratunga, R. and Haigh, R. (2006), "A theoretical framework on managing tacit knowledge for enhancing performance in the construction industry", in Annual Research Conference of the Royal Institution of Chartered Surveyors, Royal Institution of Chartered Surveyors, London, UK, pp. 534-44.

Prajogo, D.I. and McDermott, P. (2011), "Examining competitive priorities and competitive advantage in service organisations using Importance-Performance Analysis matrix", Managing Service Quality, Vol. 21, No. 5, pp. 465-83.

Rosemann, M. and Vom Brocke, J. (2015), "The six core elements of business process management", in Vom Brocke, J. and Rosemann, M. (Ed.), Handbook on Business Process Management 1, Springer, Heidelberg, Berlin, pp. 105-22.

Sadeghi, M.R., Moghimi, S.M. and Ramezan, M. (2013), "Identifying and prioritizing of effective constructs in readiness of knowledge management implementation by using fuzzy analytic hierarchy process (AHP)", Journal of Knowledge-Based Innovation in China, Vol. 5, No. 1, pp. 16-31.

Sentanin, O.F., Santos, F.C.A. and Jabbour, C.J.C. (2008), "Business process management in a Brazilian public research centre", Business Process Management Journal, Vol. 14, No. 4, pp. 483-96.

Silva, L.A., Damian, I.P.M. and Pádua, S.I.D. (2012), "Process management tasks and barriers: functional to processes approach", Business Process Management Journal, Vol. 18, No. 5, pp. 762-76.

Silva, M.G. and Sellitto, M.A. (2010), "Impactos da autonomação em sistemas produtivos: análise com apoio da árvore da realidade atual", Revista Gestão Industrial, Vol. 6, No. 1, pp. 199-216.

Syed, R., French, E., Bandara, W. et al. (2017), “What does 'Leadership' entail in public sector BPM initiatives of developing nations: Insights from an interpretative case study from Sri Lanka", in 5th International Conference on Research and Innovation in Information Systems (ICRIIS 2017), Langkawi, Malaysia.

Teece, D.J. (2007), "Explicating dynamic capabilities: The nature and microfoundations of (sustainable) enterprise performance", Strategic Management Journal, Vol. 28, No. 13, pp. 1319-50.

Trkman, P. (2010), "The critical success factors of business process management", International Journal of Information Management, Vol. 30, pp. 125-34.

Tsoukas, H. and Vladimirou, E. (2001), "What is organizational knowledge", Journal of Management Studies, Vol. 38, No. 7, pp. 973-93.

Vom Brocke, J., Zelt, S. and Schmiedel, T. (2016), "On the role of context in business process management", International Journal of Information Management, Vol. 36, No. 3, pp. 486-95. 
Wu, I.-L. and Chen, J.-L. (2014), "Knowledge management driven firm performance: the roles of business process capabilities and organizational learning", Journal of Knowledge Management, Vol. 18, No. 6, pp. 1141-64.

Schmiedel, T., Vom Brocke, J. and Recker, J. (2013), "Which cultural values matter to business process management", Business Process Management Journal, Vol. 19, pp. 292-317.

Segatto, M., Pádua, S.I.D. and Martinelli, D.P. (2013), "Business process management: a systemic approach", Business Process Management Journal, Vol. 19, No. 4, pp. 698-714.

Authors contributions: Ana Augusta Almeida de Souza dos Santos: writing and data collection. Silvia Inês Dallavalle de Pádua: managing the project. Ronaldo Bernardo Junior: writing. Emerson Lima Aredes: data collection. 